\title{
The Engineering Leader of the Future: Research and Perspectives
}

\section{Dr. Meg Handley, Pennsylvania State University, University Park}

Meg Handley is currently the Associate Director for Engineering Leadership Outreach at Penn State University. Previously, Meg served as the Director of the Career \& Corporate Connection's office at the Smeal College of Business at Penn State University. Meg completed her PhD in Workforce Education at Penn State, where she focused on interpersonal behaviors and their impact on engineering leadership potential.

Meg is a board certified coach with experience in developing students' leadership and professional competencies through teaching and one-on-one coaching. She is most interested in developing student knowledge of leadership to impact their successful transition to the workplace.

\section{Dr. Jeffery M. Plumblee II, The Citadel}

Dr. Jeffery Plumblee is an Assistant Professor in the Department of Engineering Leadership and Program Management (ELPM) in the School of Engineering (SOE) at The Citadel. Dr. Plumblee earned his BS in Civil Engineering at Clemson University (2008), Masters in Civil Engineering at Clemson University (2009), Masters of Business Administration at Clemson University (2013), and Doctorate of Philosophy in Civil Engineering at Clemson University (2013). Dr. Plumblee's dissertation research sought to better understand the relationship between sustainability and resilience in residential construction. He continued his work in resilience by helping to kick start a new business line at Fluor Corporation in Business Continuity and Disaster Management Solutions, where he primarily worked as a consultant with Fortune 100 aerospace and pharmaceutical clients.

Plumblee's research interests focus on building a more resilient society, as well as innovation in resource constrained settings (primarily humanitarian technology and delivery). Plumblee founded an international award winning organization (Clemson Engineers for Developing Countries), which has successfully completed over \$2 million of infrastructure improvements in rural Haiti. He continues his research to drive innovation of experiential learning within engineering education.

\section{Mr. Andrew Michael Erdman, The Pennsylvania State University}

Andrew M. "Mike" Erdman received his B.S. in Engineering Science from Penn State and his M.S. from USC. Erdman has also taken courses at RPI, Union, UCLA, UCSB, MIT, and Dartmouth. At Rocketdyne (Pratt \& Whitney), he helped design the Space Shuttle. As manager of Reactor Safety Analysis, Experimental Engineering, and Fluid Dynamics Technology at KAPL (Lockheed Martin), he conducted research for Naval Reactors. He currently serves as the Walter L. Robb director of Engineering Leadership and as an instructor in Engineering Science at Penn State. Erdman has chaired the local Jaycees, Department of Social Services Advisory Council, GE Share Board, and Curling Club; and served on the Human Services Planning Council, United Way, Chamber of Commerce, and Capital Fund Drive Boards of Directors. Erdman has also lectured on leadership topics at Penn State and RPI. He returned to campus frequently as a recruiter (25 years) for GE and Lockheed Martin, serving on the Penn State College of Engineering Advisory Council, helped establish an Alumni Advisory Board, and served as the President of the College of Engineering Alumni Society. Affiliations include the Penn State Alumni Association, Centre County Chapter Board of Directors, President's Club, Nittany Lion Club, ASEE, ASME, AIAA, AKC, GRCA. He has been honored with a LMC/KAPL Leadership Award, GE Phillippe Award, PSEAS Outstanding service award, Jaycee International Senatorship, and an ESM Centennial Fellowship. 


\section{Using a Systematic Review to Identify Leadership Competency Needs Across Engineering Disciplines}

\section{Background}

Since ABET and industry began calling for leadership and professional skill development in engineering students in the early 2000's, the literature involving engineering education and training has evolved to include a variety of studies and articles to address this gap in engineering curriculum.

ASEE saw an increase in interest in the topic and launched the Engineering Leadership Development Division (LEAD) as of 2015. LEAD has grown to over 1,000 members across over 400 institutions and seeks to "support the creation of engineering leadership educational programs and outcomes, viewed by those who participate in the programs and those who hire the graduating students, as the best in the world" [1]. A strategic planning committee, analyzing the drivers of change and the challenges related to engineering leadership, developed four strategic initiatives to focus research and initiatives of the division. These four initiatives highlighted the need to understand the concept of engineering leadership and how to incorporate it into engineering curriculum. The four initiatives include:

1. How to assist university administrators and faculty to understand the significant value of this new field in academia and practice

2. How to resource Engineering Leadership Education (ELE) programs, such as funds, facilities, and capable faculty and staff

3. How to effectively integrate within the curriculum, teach, and assess leadership development in engineering students from undergraduate to graduate to practicing engineers.

4. How to develop a framework/model that describes the diverse Engineering Leadership needs of companies across industries

As members of the LEAD division, the authors sought to focus on strategic initiative number four. In an effort to begin addressing this initiative, this paper seeks to provide an initial study to begin piecing together the current picture of engineering leadership across engineering disciplines. The purpose of this paper is to provide a pilot study, which outlines a method to analyze literature and compile data relative to a specific engineering discipline to begin building a framework for the diverse engineering leadership needs across industries. This particular study will focus on the needs relevant to the civil engineering discipline, with discipline referring to both the education and industry sectors. This study specifically focuses on three journal publications under the American Society of Civil Engineers to identify the themes emerging from the articles within these publications relevant to leadership needs within civil engineering. This pilot study will provide a framework to complete a larger analysis across numerous engineering disciplines in an effort to address LEAD strategic initiative four.

Since the target audience and primary authors of professional society's publications include academics and practitioners within that society's field, this research will use professional societies' publications as an assumed representative sampling of the opinions of academic and 
industry professionals in the discipline of civil engineering. This pilot research begins with using ASCE literature representing the discipline of civil engineering due to the large number of journals which include journals specifically related to leadership, management, and engineering education.

The American Society of Civil Engineers serves engineers across all career stages as they seek to "plan, design, construct, and operate society's economic and social engine- the built environment- while protecting and restoring the natural environment" [2]. The professional organization publishes 38 scholarly journals, a variety of conference proceedings, and numerous other media outlets such as news stories and books. To address changes in ABET requirements which included professional skills development, ASCE answered with an updated list of learning outcomes that included an understanding of both management and leadership principles and attitudes [3]. The priority placed on knowledge and understanding of leadership and management by ASCE, combined with the large volume of publications associated with the discipline, provides ample opportunity for a pilot study to address LEAD's strategic initiative four. Through this alignment, the research questions associated with this study include:

1. How has engineering leadership been operationalized or assessed in the discipline of civil engineering?

2. What methods have been used to teach or train leadership within the civil engineering discipline?

\section{Methods}

A systematic review of engineering leadership literature was completed using the guidelines defined by Borrego, Foster, and Froyd (2014) [4]. The authors mirrored the structure of Watson and Barrella's systematic review of sustainability assessments, as it was an exemplary illustration of the application of Borrego et al.'s guidelines [5]. The research question was broadly defined as determining the current state of education or practice in the engineering leadership literature within civil engineering, and inclusion criteria was defined as seen in the following section. The study included an initial retrieval and filtering of 64,697 published works. Once articles were filtered using the inclusion criteria, authors critically reviewed abstracts for relevance, then reviewed full texts for relevance, followed by synthesis and categorization of the data.

\section{Research Question and Inclusion Criteria}

The research questions of our study are:

1. How has engineering leadership been operationalized or assessed in the discipline of civil engineering?

2. What methods have been used to teach or train leadership within the civil engineering discipline?

The inclusion criteria based upon publication information included the following:

- The study was published between 1997 and 2017.

- The study was published in English. 
- The study discusses engineering leadership objectively

- as an inclusive term,

- or leadership within an engineering education and training context (including professional development).

Note that there were no additional geographical restraints on publisher or author.

\section{Finding and Cataloging Sources}

This study was intended to explore the existing literature of engineering leadership specifically in the context of civil engineering. The American Society of Civil Engineers article database was searched to develop a comprehensive list of articles mentioning both engineering and leadership, within the context of civil engineering. Search terms included ["engineering leadership"] and [engineering + leadership]. This led to an initial list of 77 publications (Figure 1). The journals and proceedings referenced in the study include the following:

- Journal of Leadership and Management in Engineering

- Journal of Professional Issues in Engineering Education and Practice

- Journal of Construction Engineering and Management

- Journal of Management in Engineering

- Construction Research Congress Proceedings

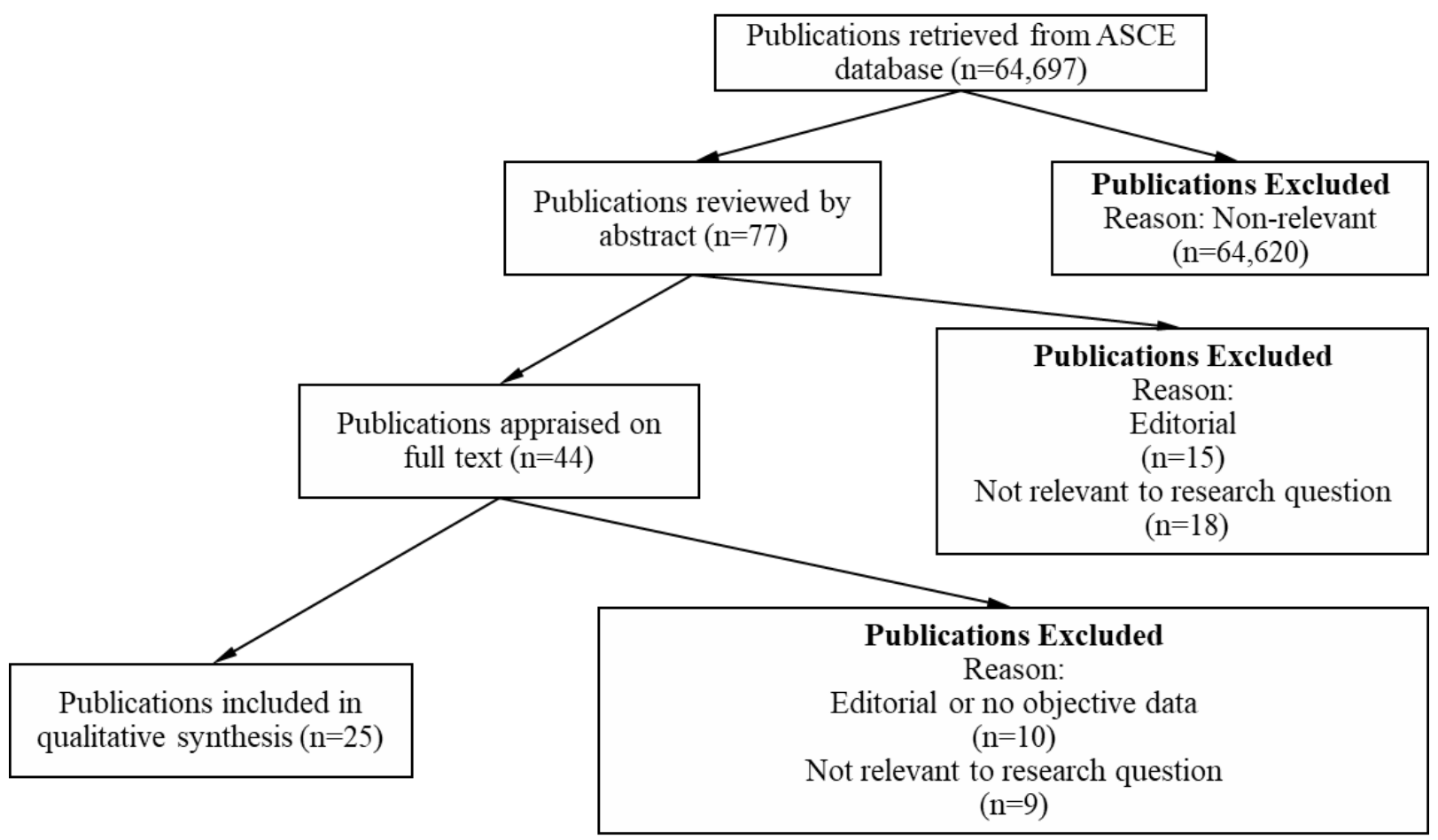

Figure 1: Search, Catalogue, Screening, and Appraisal Process Summary.

Screening and Appraisal

An initial abstract review identified 33 publications that did either not pertain to our research question or was an editorial, so these records were excluded. Most of these publications that 
were excluded were editorials broadly describing the need for engineering leadership or only tangentially mentioned engineering leadership.

A total of 44 publications were appraised based upon their full texts. An additional 10 were excluded because they were categorized as an editorial or had no objective data that could be extrapolated from the publication. Nine were excluded because they were not relevant to the research question.

Synthesis

Following screening and appraisal, 25 publications were left for synthesis. The authors categorized the publications into three categories, including the following:

- Definitions or descriptions of leadership attributes, competencies, or skills

- Assessment of leadership attributes

- Description of leadership education or training methods

\section{Results}

The 25 studies identified in the ASCE literature were categorized into three areas relevant for engineering leadership education and development. Articles were considered for both entrylevel and professional civil engineers. In some cases, the articles fell into numerous categories and are identified as such in the data analysis. All 25 studies included in the synthesis were contained within four publications, distributed as seen in Figure 2.

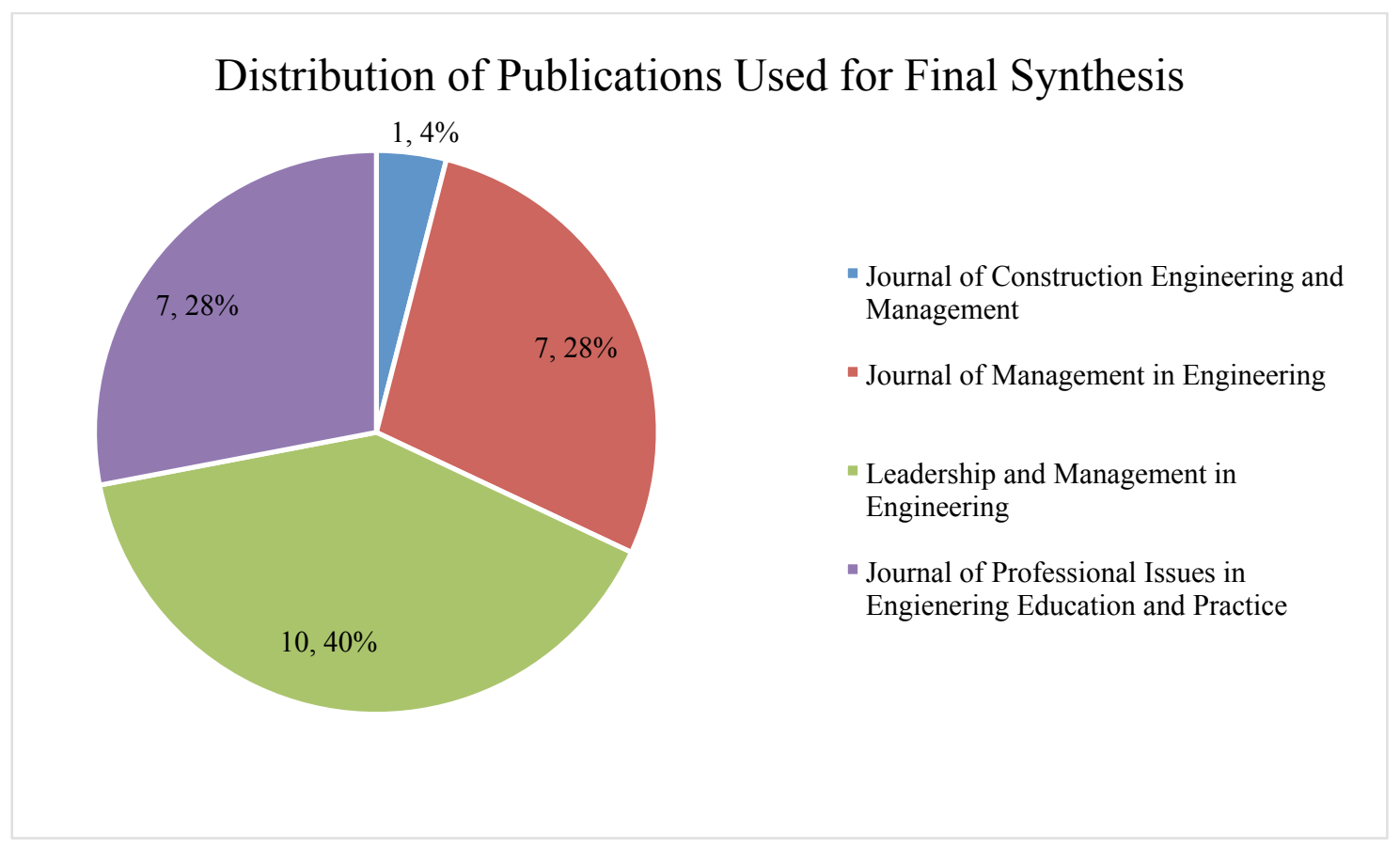

Figure 2: Distribution of studies within ASCE publications.

The purpose of this paper is to provide a framework using the systematic review process to identify and describe the leadership context within an engineering discipline. In addition, the framework by which this information is gathered and presented will be incorporated into a larger 
study where all engineering disciplines are analyzed using this method. This pilot study allows the researchers to test the methods and presentation of results in order to generate a cohesive and repeatable framework to address the totality of strategic initiative four for the LEAD division. The following sections compile the articles within their respective categories as outlined in the method section.

Category 1: Definitions or descriptions of leadership attributes, competencies, and skills This category describes articles that defined the leadership attributes associated with leadership within the civil engineering context. These definitions evolved from industry identified competencies and validation measures. Twenty-four percent ( 6 total) of the articles fell within this category. Each article involved industry validation of competencies identified as relevant for leadership either at the early-career stage or as professionals. The studies included a variety of approaches to identify leadership attributes to include qualitative and quantitative approaches, industry interviews or surveys, literature reviews, and academic perspective. The studies ranged from identifying as few as five attributes to as many as 27 (Figure 3). The competencies listed in Figure 3 were explictly identified in the articles analyzed in this study. "Communication," "Collaboration \& Teamwork," and "Vision \& Direction" appeared most frequently, being noted in at least four of the six publications. Eight attributes appeared in at least half of the publications. "Communication" was the only item that was explicitly stated in every publication.

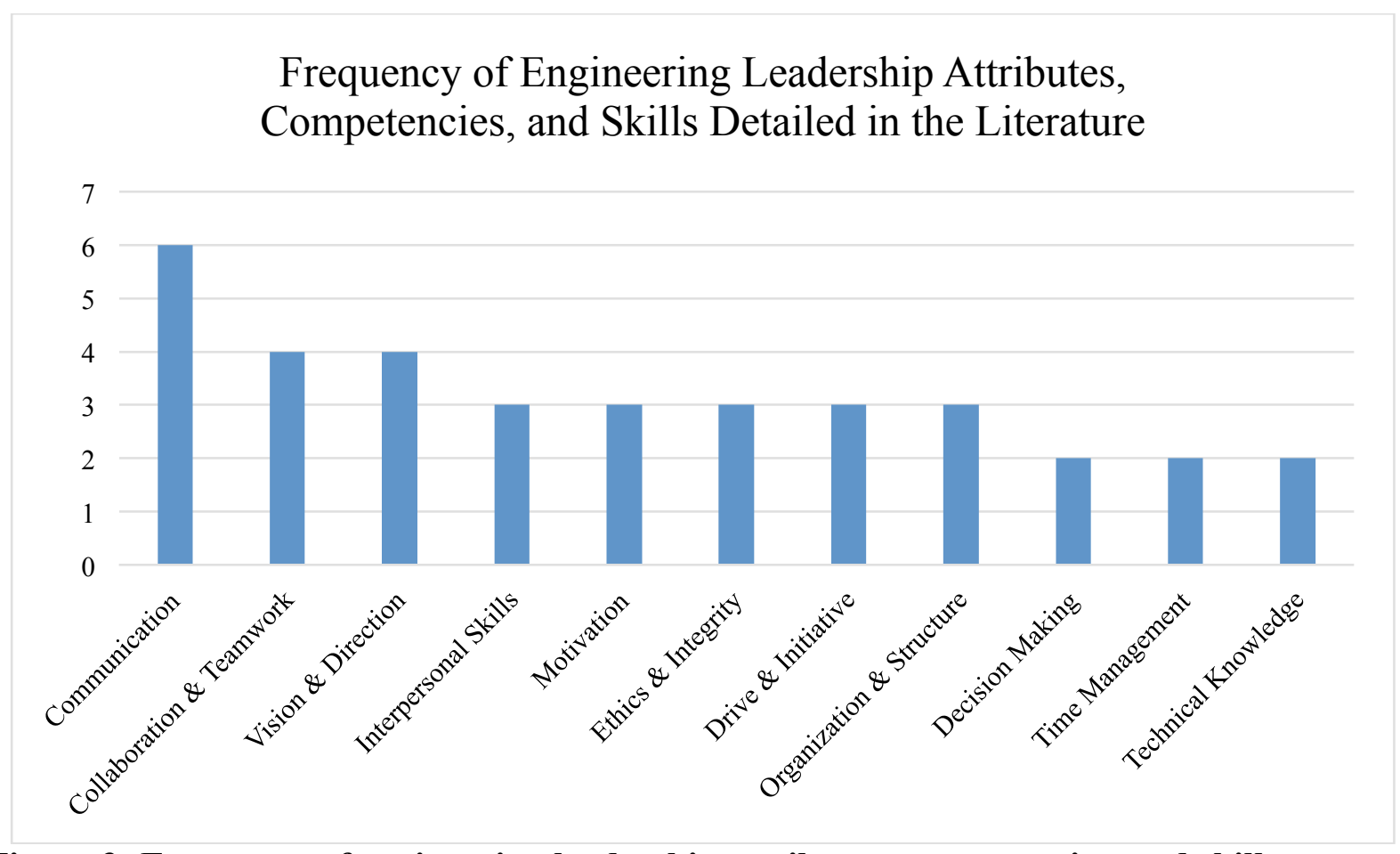

\section{Figure 3: Frequency of engineering leadership attributes, competencies, and skills.}

\section{Category 2: Assessment of leadership attributes}

This category describes articles that utilized existing assessment models to assess leadership within the civil engineering context. Thirty-two percent of the articles ( 8 total) fell within this category. Each of the articles tested the perceived leadership of a population of professionals ( 7 articles) or students (1 article) based on the leadership assessment tool selected (Table 1). 
Table 1: Summary of assessment data from literature.

\begin{tabular}{|c|c|c|c|c|}
\hline $\begin{array}{l}\text { Name of Assessment } \\
\text { Used }\end{array}$ & $\begin{array}{c}\text { Summary Focus of the } \\
\text { Assessment }\end{array}$ & $\begin{array}{c}\text { Reliability } \\
\alpha\end{array}$ & $\begin{array}{c}\text { Frequency } \\
\text { of Use }\end{array}$ & $\begin{array}{c}\text { Target } \\
\text { Population }\end{array}$ \\
\hline $\begin{array}{l}\text { Behavioral Event } \\
\text { Interview technique } \\
\text { (BEI) }\end{array}$ & $\begin{array}{l}\text { A qualitative approach to } \\
\text { identifying and coding } \\
\text { behaviors associated } \\
\text { with a competency } \\
\text { model. }\end{array}$ & NA & 1 & $\begin{array}{l}\text { 4th year } \\
\text { students }\end{array}$ \\
\hline $\begin{array}{l}\text { Campbell Leadership } \\
\text { Index (CLI) }\end{array}$ & $\begin{array}{l}\text { A leadership } \\
\text { characteristic adjective } \\
\text { list (100), depicting the } \\
\text { qualities of effective } \\
\text { leadership. }\end{array}$ & .72 & 1 & Professionals \\
\hline $\begin{array}{l}\text { Emotional Intelligence } \\
\text { Appraisal (EIA) }\end{array}$ & $\begin{array}{l}\text { Based on Daniel } \\
\text { Goleman's work in } \\
\text { Emotional Intelligence; } \\
\text { includes a self-report, } \\
360 \text { feedback, and a team } \\
\text { assessment tool. }\end{array}$ & $.85-.91$ & 1 & $\begin{array}{l}\text { Construction } \\
\text { professionals }\end{array}$ \\
\hline $\begin{array}{l}\text { Emotional Quotient } \\
\text { Inventory (EQi) }\end{array}$ & $\begin{array}{l}\text { Based on Bar-On's } \\
\text { theory of Emotional } \\
\text { Intelligence; a self-report } \\
\text { measure on emotional } \\
\text { and social competencies. }\end{array}$ & .5 & 1 & $\begin{array}{l}\text { Construction } \\
\text { executives }\end{array}$ \\
\hline $\begin{array}{l}\text { Leadership Practices } \\
\text { Inventory (LPI) }\end{array}$ & $\begin{array}{l}\text { A 360-leadership } \\
\text { assessment measuring } \\
\text { behaviors associated } \\
\text { with leadership } \\
\text { competencies. Provides } \\
\text { a model of leadership } \\
\text { development and } \\
\text { includes a professional } \\
\text { and student version. }\end{array}$ & .82 & 2 & Professionals \\
\hline $\begin{array}{l}\text { Myers-Briggs Type } \\
\text { Indicator (MBTI) }\end{array}$ & $\begin{array}{l}\text { Identifies personality } \\
\text { preferences and } \\
\text { tendencies. }\end{array}$ & $.61-.87$ & 1 & Professionals \\
\hline $\begin{array}{l}\text { Multifactor Leadership } \\
\text { Questionnaire (MLQ) }\end{array}$ & $\begin{array}{l}\text { Measures leadership } \\
\text { behaviors related to } \\
\text { transformational and } \\
\text { transactional leadership } \\
\text { theories; includes } \\
\text { specific behavioral } \\
\text { descriptors. }\end{array}$ & $.69-.83$ & 3 & $\begin{array}{l}\text { Construction } \\
\text { professionals; } \\
\text { Construction } \\
\text { executives; } \\
\text { Professionals }\end{array}$ \\
\hline
\end{tabular}


For more information on these and other leadership assessment tools, readers may reference Feedback to Managers: A Guide to Reviewing and Selecting Multirater Instruments for Leadership Development [6].

Category 3: Description of leadership education or training methods

This category includes articles that described educational and training methods utilized for civil engineering education or professional development. Forty-four percent of the articles (11 total) fell within this category. An additional two articles were added to this category that were also included in Category 1 (Definitions or descriptions of leadership attributes, competencies, and skills), bringing the total analyzed for this category to 13 articles, making this category the largest in the sample. The studies included in this section described classes or programs that could incorporate leadership development. Three studies included strategies for assessing leadership development within an educational setting or professional training program.

As seen in Table 2, the largest percentage of educational or training methods discussed within this category was for classes (46\%), with full programs and leadership development programs representing $31 \%$ of the sample, and those falling into the "Other or not applicable" category at $23 \%$.

Table 2: Summary of educational and training methods data from literature.

\begin{tabular}{|lcc|}
\hline & Frequency & $\begin{array}{c}\text { Percentage of } \\
\text { publications }\end{array}$ \\
\hline A) Educational or Training Method & & \\
PBL/ experience focused & 6 & $46 \%$ \\
Mentorship and coaching & 3 & $23 \%$ \\
Personal development & 2 & $15 \%$ \\
Other or N/A & 2 & $15 \%$ \\
\hline B) Demographics of Participants & & \\
Undergraduate student & 5 & $38 \%$ \\
$\quad$ Graduate student & 3 & $23 \%$ \\
Professional & 3 & $23 \%$ \\
Mixed & 2 & $15 \%$ \\
\hline C) Type of Intervention & & \\
Class & 6 & $36 \%$ \\
Program & 4 & $23 \%$ \\
Other or N/A & 3 & \\
\hline D) Method of Identifying Target Attributes & & $15 \%$ \\
Industry & 2 & $15 \%$ \\
Professional organizations or accreditation boards & 2 & $23 \%$ \\
Literature & 3 & $46 \%$ \\
Other or N/A & 6 & \\
\hline
\end{tabular}


The leadership development opportunities discussed in publications for this study were targeting undergraduate students, graduate students, and professionals, with some studies incorporating a combination of the aforementioned groups, also seen in Table 2. $46 \%$ of the opportunities discussed in the literature focused on experience-based leadership development, such as projectbased learning. $23 \%$ of the opportunities focused on mentorship, coaching, and peer learning, and $15 \%$ focused on some other type of personal development.

Each of the articles in category 3 mention associated learning outcomes or desired leadership attributes. It was unclear how some of these attributes were derived from, but of those that did indicate the source, $15 \%$ sought the attributes from industry, $15 \%$ from professional organizations (ASCE) or accreditation boards (ABET), and 23\% from a literature review (Table 2).

\section{Discussion}

The systematic review method was used in this pilot study to identify the current state of knowledge and practice related to engineering leadership within the civil engineering field. Using this approach this study sought to identify characteristics of leadership and leadership education within the Civil Engineering discipline and then reflect on how this method could be used in a larger study across engineering disciplines. This section outlines the findings from the literature related to leadership within the Civil Engineering discipline.

1. How has engineering leadership been operationalized or assessed in the discipline of civil engineering?

2. What methods have been used to teach or train leadership within the civil engineering discipline?

The following sections will address the findings associated with each of the research questions.

Operationalizing and assessing leadership within the Civil Engineering discipline

The six articles which specifically outlined competencies for leadership within the Civil Engineering industry span across the 20 years of this study. Early leadership competency models tended to focus on a skills approach which posits that skills needed to be successful are different depending the level of leadership one holds [7]. As an example, Farr, Walesh, \& Forsythe (1997) discuss the leadership skills needed for early career engineers as being technically oriented initially and more human centered as they progress in leadership roles. Odusami (2002) utilizes Katz (1974) model as a framework for observing leadership competencies in professional construction workers. Contrasting these articles, more recent studies indicate the importance early-career engineers demonstrating people skills [10], [11]. Interpersonal competences tied second with communication as the most important leadership competencies for early-career engineers in Hartmann, Jarens, and Stephens (2017). This shift in skill need reveals the importance of incorporating interpersonal skill development, into education and training during the early-career stage for civil engineers. Interpersonal interactions are defined as "having people skills and the ability to build relationships and resolve conflicts" [11] and the "ability to work with people from different backgrounds, disciplines, or cultures and with different perspectives" [10]. Riley, Horman, \& Mesner (2008) developed a graduate program designed to positively impact interpersonal skills in engineering graduates. One competency which did not emerge as much as expected was technical competency. Technical competency only appeared 
twice in the synthesis, once in entry-level competency descriptions [10] and once in professional competency descriptions [9]. This lack of emphasis on technical competency is surprising considering the historical focus on technical skills within engineering.

The assessments from the literature also align with interpersonal skill development. Three of the eight studies focused on assessing emotional intelligence particularly related to leadership and effective performance. Emotional intelligence has been studied within the context of effective performance and defined as the following "an ability to recognize, understand, and use emotional information about oneself or others that leads to or causes effective or superior performance" (p.5)[13]. Emotional intelligence (EI) competencies are specifically defined with four competency clusters: self-awareness, self-management, social awareness and relationship management [14]. Within these competency clusters, EI theories center on relationships, with interpersonal skills being essential for effective leadership performance [15]. Research suggests strong relationships between emotional intelligence, interpersonal, and leadership abilities [14], $[16]-[18]$.

Like the previous listed studies, the two studies related to Civil Engineering found positive relationships between EI competencies and leadership effectiveness [19], [20]. In particular, Butler et al. (2006) noted construction leaders lacking in EI skills related to interpersonal competencies to include: empathy, interpersonal interactions, and social responsibility. EI scholars argue that technical or cognitive ability alone does not explain the differences in star performers particularly related to leadership performance [21]-[23]. Jensen et al. (2007) describes this difference in performers by stating "It can then be argued that, if IQ is held constant, EI abilities will be helpful in distinguishing leaders that are more effective" (p.25). The EI research related to civil engineers supports the need for education and development that includes EI abilities for effective leadership performance.

Transformational leadership also emerged as a common theme within the leadership assessment studies. Construction professionals' leadership styles were assessed relative to transformational verses transactional leadership styles and the perceived effectiveness of the two styles. These styles fall into a category of leadership related to understanding the leader-follower relationship. Transformational leaders seek to build up followers, motivating intrinsically towards a shared goal through an understanding of follower developmental needs [25]. Transactional leaders see extrinsic motivators as means to achieve goals through follower actions. Transformational leaders inspire, transactional leaders seek to reward only when an effort is made [26]. Construction leaders were found to be more effective when behaving in ways consistent with transformational leadership [19], [27]. Transformational leadership behaviors were also shown to impact innovative cultures and solutions [28]. The transactional tendencies of construction workers was identified as a masculine approach to leadership, a telling and directive style focused on the importance of achievement and material awards and indicative of the male dominated field [28]. Conversely, transformational leadership aligns with feminine values of relationship building and interpersonal competencies [28]. The effectiveness of the use of transformational leadership styles require that civil engineering consider incorporating emotional intelligence and interpersonal skill development into education and training initiatives. 
Each of the studies assessing leadership performance identified in this review utilized a valid measure to asses leadership behavior with each finding suggesting that leadership can and should be developed and set as a priority within education and training initiatives. The final category, description of education and training methods, focused on strategies within higher education (10 out of 13 articles) as opposed to professional development (3 out of 13 articles). Many of the studies used literature reviews or accreditation requirements to structure classroom or program learning objectives. One program used industry feedback to establish a list of industry-identified characteristics needed for leadership within the civil engineering context. This aligns with other literature identifying the need for a unified approach to defining engineering leadership within each discipline context [29]. The course and program descriptions associated with this study lack implementation of valid leadership assessments. As identified in the assessment section of this study, valid and reliable leadership assessments are being used in the professional setting to assess leadership abilities and development and begs the question, "why not in academia?" Awareness, cost, and a lack of understanding or training may contribute to the lack of use in the education setting. Resources are available to educate and train engineering educators on these assessments [6]. While these assessments are not specific to the context of civil engineering leadership (or engineering leadership in general), they can be helpful until valid contextualized instruments have been created as is the intent with the research initiatives of Cox, Ahn, \& Zhu (2012) and Hartmann, Jarens, and Stephens (2017).

Methods of teaching or training leadership within civil engineering The educational and training initiatives identified in this review are heavily oriented to experiential learning theories in the form of project-based learning (PBL). These strategies are important for use in courses where the goal is to develop a skill that requires students to construct meaning from experiences as opposed to more cognitive approaches which focus on learning from a telling and explaining perspective. The project-based learning approaches described in the studies in this review provided simulation experiences and real-world problems to practice both technical problem-solving and leadership. In some cases the PBL-based approaches provided reflection activities, but in other cases did not. Successful educational initiatives seeking to develop young adults require action and reflection [30]. For professionals, coaching was used to assist in reflecting on experiences in a leadership development program. These elements of the educational initiatives associated with civil engineering are positive related to the findings from the current study.

One final theme that emerged across studies discussed the need for civil engineers to understand public policy and to lead in the public sector. This is a somewhat unique attribute of this engineering discipline as many civil engineers work to build public areas- the built environmentrequiring professionals be able to lead and interact with both technical experts and politicians or public service officials. Additionally, articles encouraged civil engineers to engage in leading the federal, state, and local levels.

Reflection on the systematic review process

A key objective of this paper was to demonstrate and reflect upon the use of the systematic review process as a method for exploring the descriptive nature of leadership across engineering disciplines. First, this method fits as an effective way to explore the use of more mature social science fields as it relates to the interdisciplinary nature of engineering education and leadership 
[4]. The systematic review is useful in describing state of knowledge or practice on a topic and is a useful approach in this case to compile and review the established methods used in assessing leadership within the civil engineering context. The method provides an organized approach to selecting and synthesizing data to provide a picture of an emerging phenomenon that is not fully defined and uses inter-disciplinary concepts. The process and synthesis approaches are relatively simplistic and provide an overall picture of the application of leadership theory, study, and education/training within a particular industry. For this reason we would recommend pursuing a larger effort using the systematic review method to provide a picture of engineering leadership across all engineering disciplines. Organizing this process must include specific instructions for inclusion criteria. The researchers found numerous declarative articles lacking a data driven approach making it challenging to sift through the data to find what is relevant to this particular study. The lack of data driven approaches is also indicative of the need for more rigorous social science oriented studies to address the calls for operationalizing leadership within the engineering context as well as creating valid assessment tools. The data driven studies identified here resulted in competency lists but leave the reader to interpret the effective behaviors associated with the competency. Interpersonal skills is an example of a competency riddled with various interpretations and lack of consistency in definition [31]. Specific and measurable behaviors are identified through rigorous competency model studies and are a need identified through this analysis.

\section{Conclusions}

In conclusion, the systematic review process revealed the following regarding leadership within the civil engineering industry:

- Over a period of 20 years, literature consistently identifies communication, collaboration \& teamwork, and vision \& direction as critical competencies towards leadership.

- Over that same 20 year period, interpersonal competency themes have increased in their perceived importance.

- Emotional Intelligence is being used as a resource for educators and trainers for prediction of effective leadership and a tool for interpersonal competency development.

- Valid leadership assessments utilized in industry should also be considered for use in higher education purposes, particularly for PBL approaches.

LEAD division's strategic initiative four should be grounded upon an expanded systematic review across all engineering disciplines' professional society journals that results in both a cross-discipline analysis and industry specific picture of the current state of knowledge and practice within each industry related to leadership. Until a valid leadership assessment is completed for engineering leaders that is appropriate across sectors, the well-established field of research in leadership provides valid measures that can be used to assess leadership within the education sector. However, it would be beneficial to identify and recommend the most applicable assessment to the leadership competency needs identified within each engineering discipline. Ultimately, this analysis served as a pilot to explore the use of the systematic review as a method for addressing the needs of the LEAD division's strategic initiative four and the researchers plan to expand this approach to include all engineering disciplines. 


\section{References}

[1] LEAD, “ASEE Engineering Leadership Development DIvision.” [Online]. Available: http://lead.asee.org/. [Accessed: 12-Jan-2018].

[2] ASCE, "American Society of Civil Engineers." [Online]. Available: https://www.asce.org/about_asce/. [Accessed: 21-Jan-2018].

[3] T. J. Siller, M. Asce, A. Rosales, J. Haines, and A. Benally, "Development of undergraduate students' professional skills," J. Prof. Issues Eng. Educ. Pract., vol. 135, no. July, pp. 102-108, 2009.

[4] M. Borrego, M. J. Foster, and J. E. Froyd, "Systematic literature reviews in engineering education and other developing interdisciplinary fields," J. Eng. Educ., vol. 103, no. 1, pp. 45-76, 2014.

[5] M. K. Watson and E. Barrella, "A Systematic Review of Sustainability Assessments in ASEE Proceedings," in American Society for Engineering Education, 2017, vol. 2003.

[6] J. B. Leslie, Feedback to managers: A guide to reviewing and selecting multirater instruments for leadership development. Greensboro, NC: Center for Createive Leadership, 2013.

[7] R. L. Katz, "Skills of an effective administrator," Harv. Bus. Rev., vol. September/, pp. 90-102, 1974.

[8] J. V. Farr, S. G. Walesh, and G. B. Forsythe, "Leadership development for engineering managers," J. Manag. Eng., vol. 13, no. 4, pp. 38-41, 1997.

[9] K. T. Odusami, "Perceptions of Construction Professionals Concerning Important Skills of Effective Project Leaders," J. Manag. Eng., vol. 18, no. 2, pp. 61-67, 2002.

[10] M. Cox, O. Cekic, B. Ahn, and J. Zhu, "Engineering professionals' expectations of undergradate engineering students," Leadersh. Manag. Eng., vol. 12, pp. 60-70, 2012.

[11] B. L. Hartmann, C. M. Stephens, and C. T. Jahren, "Validating the importance of leadership themes for entry-level engineering positions," J. Prof. Issues Eng. Educ. Pract., vol. 143, no. Abet, pp. 1-7, 2017.

[12] D. R. Riley, M. J. Horman, and J. I. Messner, "Embedding leadership development in construction engineering and management education," J. Prof. Issues Eng. Educ. Pract., vol. 134, no. 2, pp. 143-151, 2008.

[13] R. E. Boyatzis and F. Sala, "Assessing emotional intelligence competencies," in The Measurement of Emotional Intelligence, Glenn Geher, Ed. Nova Science Publishers, 2004.

[14] R. E. Boyatzis, D. Goleman, and K. S. Rhee, "Clustering competence in emotional intelligence: Insights from the emotional competence inventory," in The handbook of emotional intelligence, R. Bar-On and J. D. . Parker, Eds. San Francisco, CA: JosseyBass, 2000, pp. 343-380.

[15] D. Goleman, Emotional Intelligence. New York, NY: Bantam Books, 1995.

[16] C. Saarni, The development of emotional intelligence. New York, NY: The Guildford Press, 1999.

[17] N. S. Schutte et al., "Emotional Intelligence and Interpersonal Relations," J. Soc. Psychol., vol. 141, no. 4, pp. 523-536, 2001.

[18] R. Sunindijo and P. X. W. Zou, "The roles of emotional intelligence, interpersonal skill and transforamational leadership in improving construction safety," Australas. J. Constr. Econ. Build., vol. 13, no. 3, pp. 97-113, 2013.

[19] C. J. Butler and P. S. Chinowsky, "Emotional intelligence and leadership behavior in 
construction executives," J. Manag. Eng., vol. 22, no. 3, pp. 119-125, 2006.

[20] R. Sunindijo, B. Hadikusumo, and S. Ogunlana, "Emotional intelligence and leadership styles in construction project management," J. Manag. Eng., vol. 23, no. 4, pp. 166-170, 2007.

[21] D. Goleman, "What it takes to achieve managerial success," TD Talent Dev., vol. 68, no. 11, pp. 48-52, 2014.

[22] M. Higgs, "A study of the relationship between emotional intelligence and performance in UK call centres," J. Manag. Psychol., vol. 19, no. 4, pp. 442-454, 2004.

[23] T. A. Judge, A. E. Colbert, and R. Llies, "Intelligence and leadership: A quantitative review and test of theoretical propositions," J. Appl. Psychol., vol. 89, no. 542-552, 2004.

[24] S. Jensen, C. Kohn, S. Rilea, R. Hannon, and G. Howells, "Emotional intelligence: A literature review," Publ. Dep. Psychol. Univ. Pacific, pp. 10-85, 2007.

[25] J. M. Burns, Leadership. New York, NY: Harper and Row, 1978.

[26] B. M. Bass, Leadership and performance beyond expectations. New York, NY: Free Press, NY, 1985.

[27] A. Chan and E. Chan, "Impact of Perceived Leadership Styles on Work Outcomes: Case of Building Professionals.," J. Constr. Eng. Manag., vol. 131, no. 4, pp. 413-422, 2005.

[28] I. Chan, A. Liu, and R. Fellows, "Role of leadership in fostering an innovation climate in construction firms," J. Manag. Eng., vol. 30, no. 6, p. 6014003, 2014.

[29] D. R. Simmons, N. A. Clegorne, and T. Woods-Wells, "Leadership paradigms in construction: Critical review to inform research and practice," J. Manag. Eng., vol. 33, no. 4, p. 2517001, 2017.

[30] J. Nagaoka, C. A. Farrington, S. B. Ehrlich, and R. D. Heath, "Foundations for young adult success: A development framework," no. June, pp. 1-110, 2015.

[31] Handley, M.H. "Interpersonal behaviors of early-career engineers identified by engineering leaders across three engineering disciplines," Penn State University, 2017. 